\title{
Ultrahigh Molecular Weight Linear Block Copolymers: Rapid Access by Reversible-Deactivation Radical Polymerization and Self-Assembly into Large Domain Nanostructures
}

\author{
Jose Kenneth D. Mapas, ${ }^{\dagger}$ Tim Thomay, ${ }^{\ddagger}$ Alexander N. Cartwright, ${ }^{\ddagger}$ Jan Ilavsky, ${ }^{\S}$ Javid Rzayev ${ }^{*,+}$ \\ ${ }^{+}$Department of Chemistry, University at Buffalo, The State University of New York, Buffalo, New York 14260-3000 \\ ${ }^{\ddagger}$ Department of Electrical Engineering, University at Buffalo, The State University of New York, Buffalo, New York 14260- \\ 1900 \\ ${ }^{\S}$ Advanced Photon Source Division, Argonne National Laboratory, Argonne, Illinois 60439
}

\section{Table of Contents}

Synthesis and NMR characterization of PSM-PS block copolymers.................................... S1

Figure S1 (Kinetics of $\mathrm{Cu}$ wire-mediated MMA polymerization) ..................................... S8

Figure S2 (Kinetics of $\mathrm{Cu}$ wire-mediated HEMA polymerization) ........................................ S8

Figure S3 (SEC traces of PSM-PS before and after washings) ......................................... S9

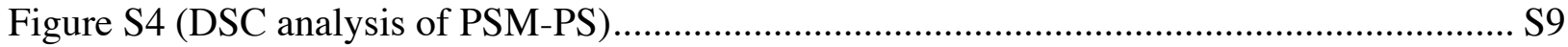

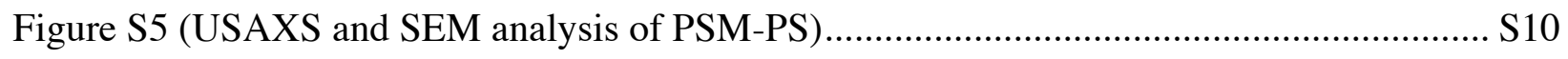




\section{Synthesis and NMR characterization of PSM-PS block copolymers}

SK-1: Poly(SM) $\left(M_{\mathrm{n}}=512,600 \mathrm{~g} / \mathrm{mol}, 1.092 \mathrm{~g}, 2.07 \mu \mathrm{mol}\right)$ and AIBN (30 $\mu \mathrm{L}$ of $7 \mathrm{mM}$ stock solution, $0.21 \mu \mathrm{mol})$ were dissolved in $(17.2 \mathrm{~mL}, 165.3 \mathrm{mmol})$ of styrene in a reaction flask equipped with a stir bar. This mixture was allowed to stir until the solids were completely dissolved. The mixture was then bubbled with $\mathrm{N}_{2}$ for 15 minutes, and placed in an oil bath at 65 ${ }^{\circ} \mathrm{C}$. After $24 \mathrm{~h}$, the flask was cooled to room temperature and the contents were diluted with dichloromethane and precipitated in hexanes (twice). The resulting polymer was suspended in boiling acetonitrile to remove residual poly(SM) homopolymer. The polymer was then dried overnight under vacuum to yield a powdery solid $(0.918 \mathrm{~g})$. SEC (polystyrene calibration): $M_{\mathrm{n}}=$ $176 \mathrm{~kg} / \mathrm{mol}, \oplus=1.49 ;{ }^{1} \mathrm{H}$ NMR: $n(\mathrm{PS})=4,362$.

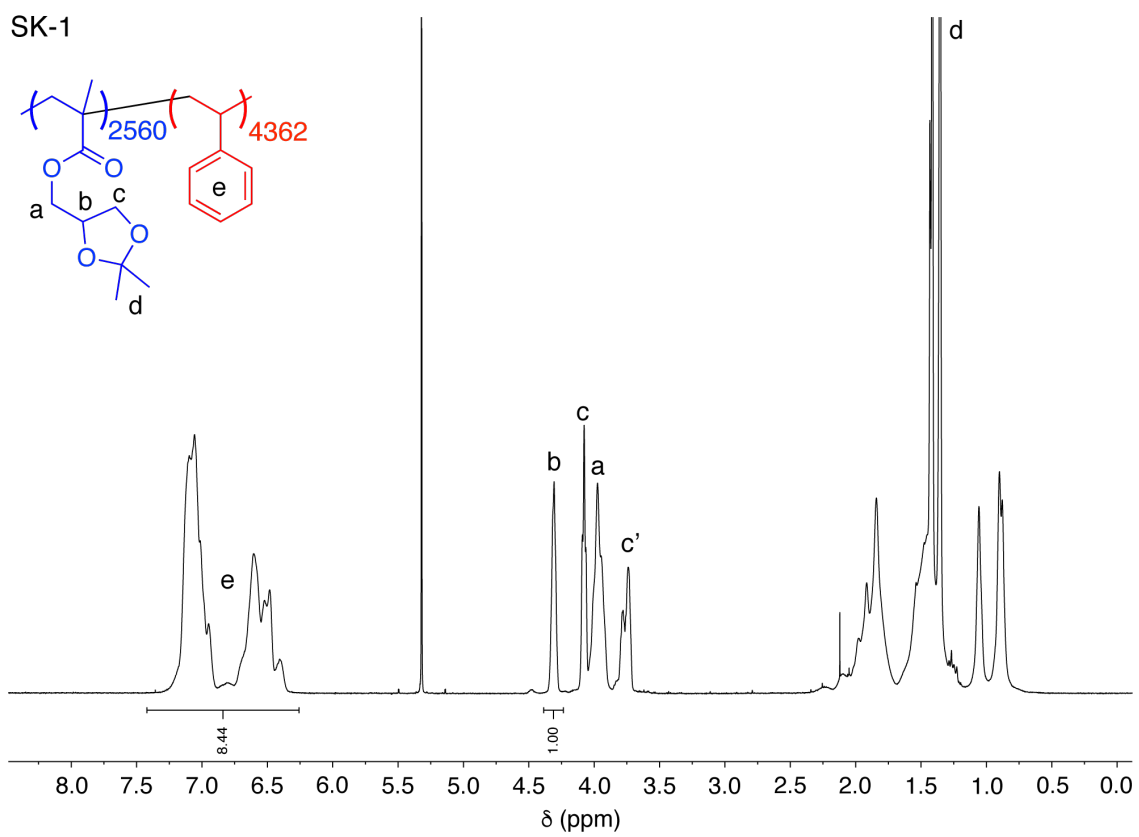


SK-2 : Poly(SM) $\left(M_{\mathrm{n}}=401,900 \mathrm{~g} / \mathrm{mol}, 0.096 \mathrm{~g}, 0.24 \mu \mathrm{mol}\right)$ and AIBN $(3.4 \mu \mathrm{L}$ of $7 \mathrm{mM}$ stock solution, $0.02 \mu \mathrm{mol})$ were dissolved in $(1.1 \mathrm{~mL}, 9.25 \mathrm{mmol})$ of styrene in a reaction flask equipped with a stir bar. This mixture was allowed to stir until the solids were completely dissolved. The mixture was then bubbled with $\mathrm{N}_{2}$ for 15 minutes, and placed in an oil bath at 65 ${ }^{\circ} \mathrm{C}$. After $24 \mathrm{~h}$, the flask was cooled to room temperature and the contents were diluted with dichloromethane and precipitated in hexanes (twice). The resulting polymer was suspended in boiling acetonitrile to remove residual poly(SM) homopolymer. The polymer was then dried overnight under vacuum to yield a powdery solid $(0.094 \mathrm{~g})$. SEC (polystyrene calibration): $M_{\mathrm{n}}=$ $296 \mathrm{~kg} / \mathrm{mol}, \oplus=1.63 ;{ }^{1} \mathrm{H} \mathrm{NMR}: n(\mathrm{PS})=2,880$.

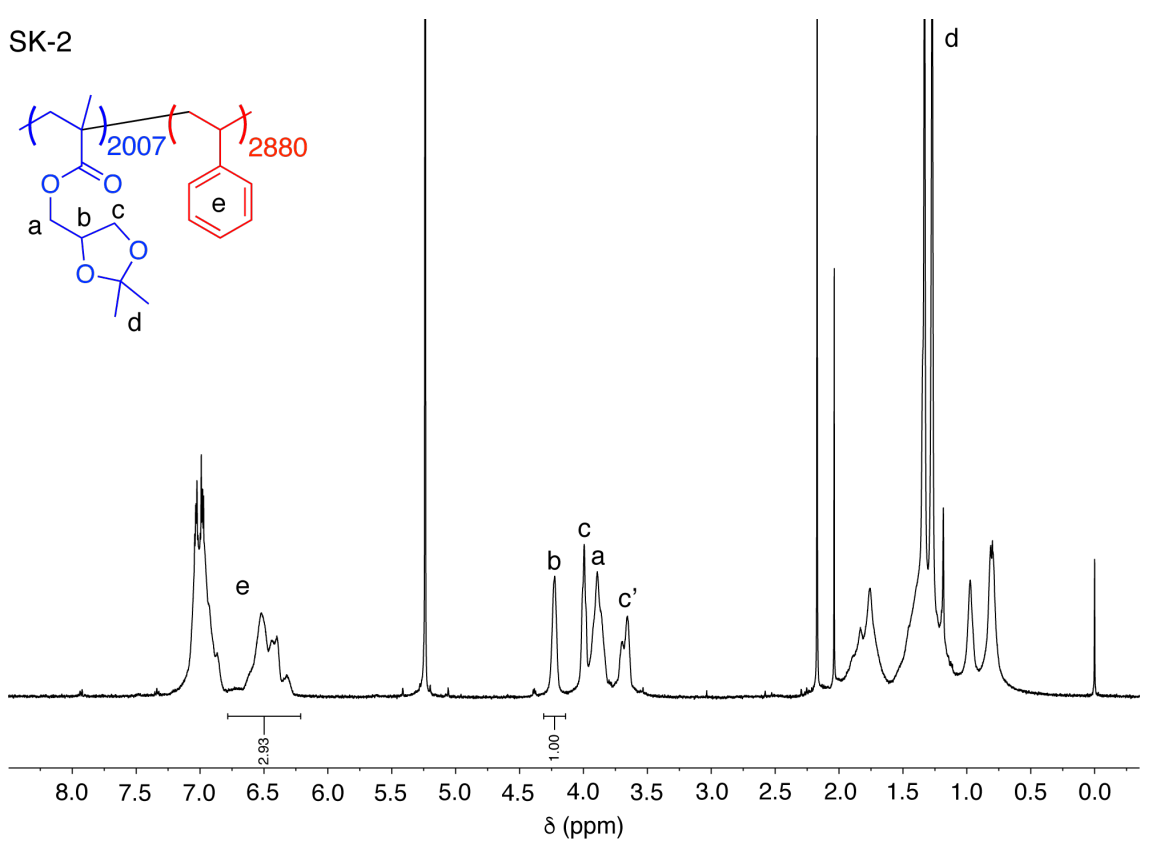


SK-3: Poly(SM) $\left(M_{\mathrm{n}}=512,600 \mathrm{~g} / \mathrm{mol}, 0.991 \mathrm{~g}, 1.88 \mu \mathrm{mol}\right)$ and AIBN $(20 \mu \mathrm{L}$ of $7 \mathrm{mM}$ stock solution, $0.14 \mu \mathrm{mol})$ were dissolved in $(31.2 \mathrm{~mL}, 271.8 \mathrm{mmol})$ of styrene in a reaction flask equipped with a stir bar. This mixture was allowed to stir until the solids were completely dissolved. The mixture was then bubbled with $\mathrm{N}_{2}$ for 15 minutes, and placed in an oil bath at 65 ${ }^{\circ} \mathrm{C}$. After $24 \mathrm{~h}$, the flask was cooled to room temperature and the contents were diluted with dichloromethane and precipitated in hexanes (twice). The resulting polymer was suspended in boiling acetonitrile to remove residual poly(SM) homopolymer. The polymer was then dried overnight under vacuum to yield a powdery solid $(1.02 \mathrm{~g})$. SEC (polystyrene calibration): $M_{\mathrm{n}}=$ $213 \mathrm{~kg} / \mathrm{mol}, \emptyset=1.39 ;{ }^{1} \mathrm{H} \mathrm{NMR}: n(\mathrm{PS})=8,341$.

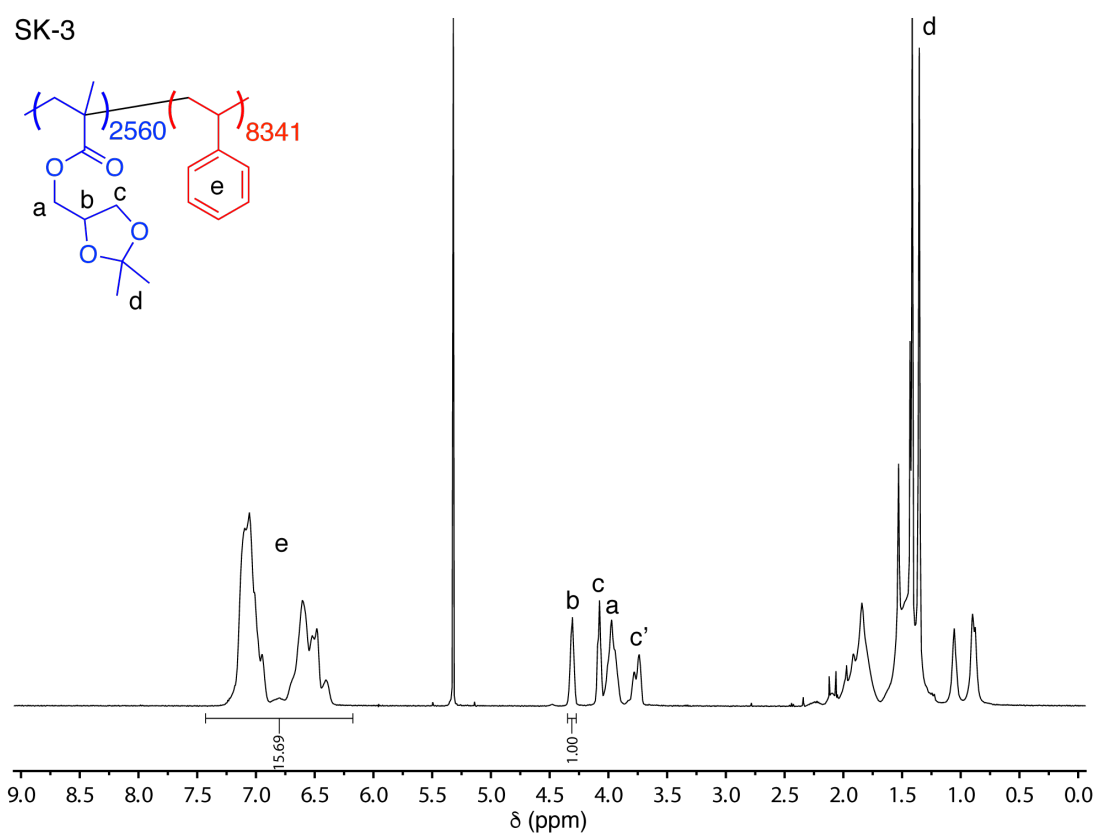


SK-4: Poly(SM) $\left(M_{\mathrm{n}}=431,900 \mathrm{~g} / \mathrm{mol}, 0.621 \mathrm{~g}, 1.48 \mu \mathrm{mol}\right)$ and AIBN $(20 \mu \mathrm{L}$ of $7 \mathrm{mM}$ stock solution, $0.14 \mu \mathrm{mol})$ were dissolved in $(12.5 \mathrm{~mL}, 108.5 \mathrm{mmol})$ of styrene in a reaction flask equipped with a stir bar. This mixture was allowed to stir until the solids were completely dissolved. The mixture was then bubbled with $\mathrm{N}_{2}$ for 15 minutes, and placed in an oil bath at 65 ${ }^{\circ} \mathrm{C}$. After $24 \mathrm{~h}$, the flask was cooled to room temperature and the contents were diluted with dichloromethane and precipitated in hexanes (twice). The resulting polymer was suspended in boiling acetonitrile to remove residual poly(SM) homopolymer. The polymer was then dried overnight under vacuum to yield a powdery solid $(1.116 \mathrm{~g})$. SEC (polystyrene calibration): $M_{\mathrm{n}}=$ $427 \mathrm{~kg} / \mathrm{mol}, \oplus=1.64 ;{ }^{1} \mathrm{H} \mathrm{NMR}: n(\mathrm{PS})=6,554$.

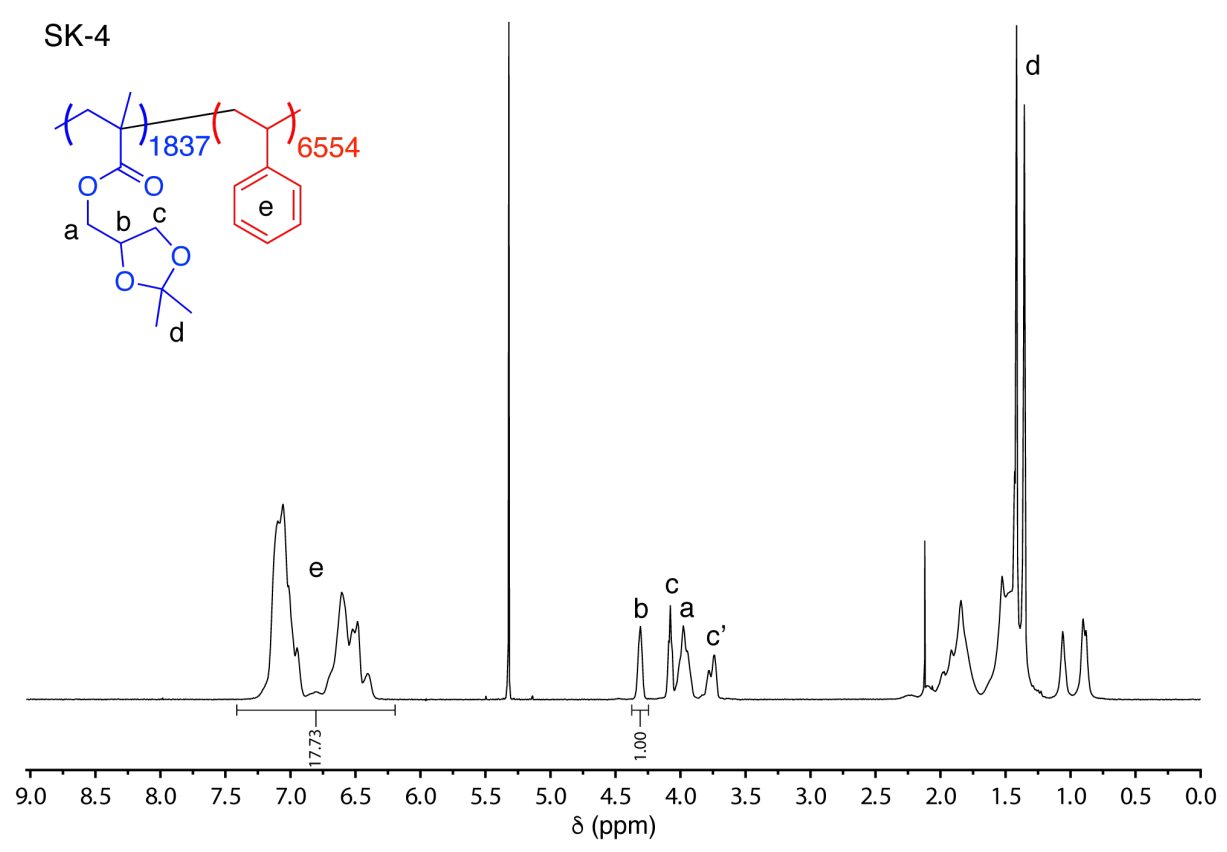


SK-5: Poly(SM) $\left(M_{\mathrm{n}}=401,900 \mathrm{~g} / \mathrm{mol}, 0.056 \mathrm{~g}, 0.14 \mu \mathrm{mol}\right)$ and AIBN $(1.9 \mu \mathrm{L}$ of $7 \mathrm{mM}$ stock solution, $0.013 \mu \mathrm{mol})$ were dissolved in $(1.4 \mathrm{~mL}, 11.9 \mathrm{mmol})$ of styrene in a reaction flask equipped with a stir bar. This mixture was allowed to stir until the solids were completely dissolved. The mixture was then bubbled with $\mathrm{N}_{2}$ for 15 minutes, and placed in an oil bath at 65 ${ }^{\circ} \mathrm{C}$. After $24 \mathrm{~h}$, the flask was cooled to room temperature and the contents were diluted with dichloromethane and precipitated in hexanes (twice). The resulting polymer was suspended in boiling acetonitrile to remove residual poly(SM) homopolymer. The polymer was then dried overnight under vacuum to yield a powdery solid $(0.085 \mathrm{~g})$. SEC (polystyrene calibration): $M_{\mathrm{n}}=$ $339 \mathrm{~kg} / \mathrm{mol}, \oplus=1.76 ;{ }^{1} \mathrm{H}$ NMR: $n(\mathrm{PS})=5,419$.

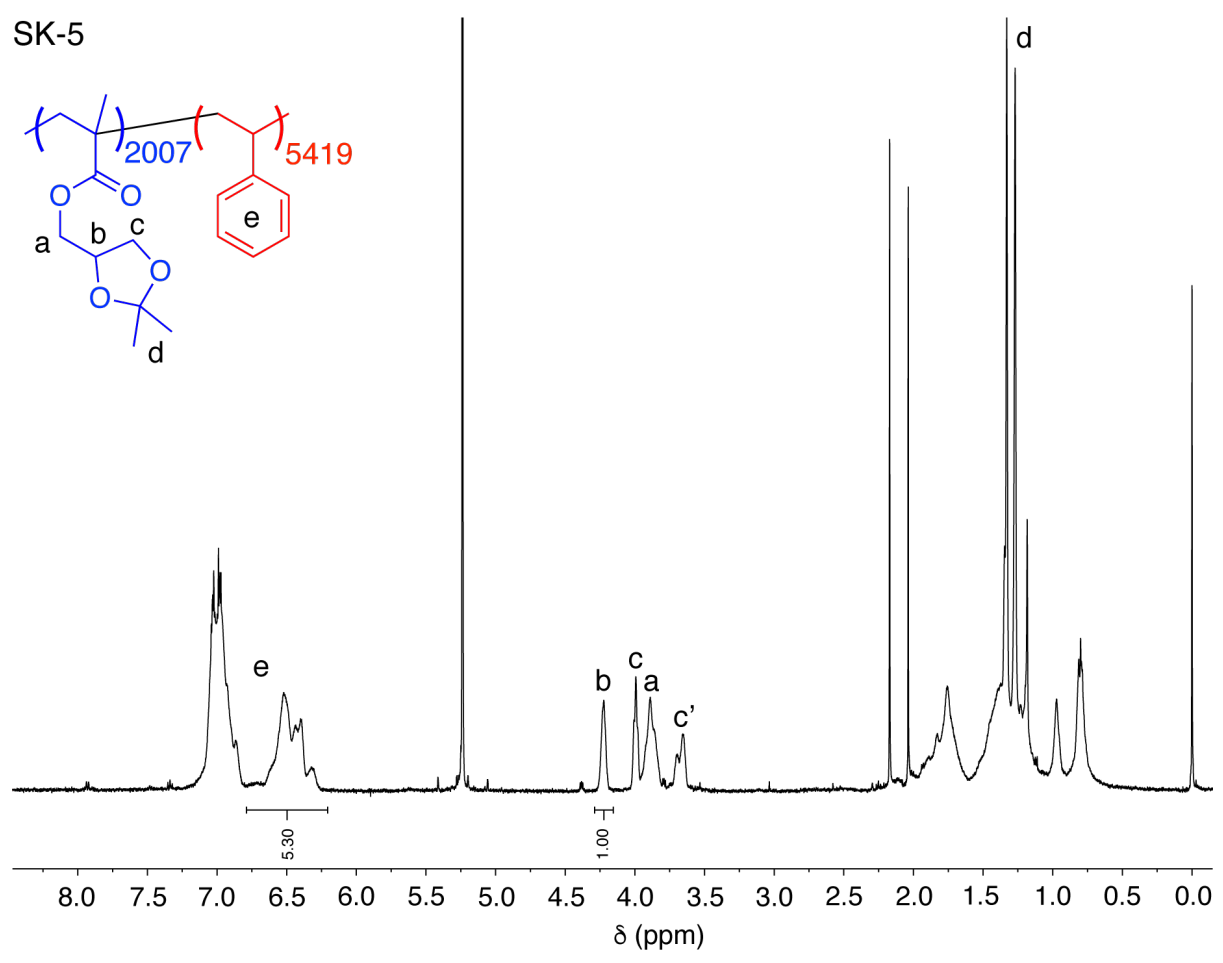


SK-6: Poly(SM) $\left(M_{\mathrm{n}}=431,900 \mathrm{~g} / \mathrm{mol}, 0.621 \mathrm{~g}, 1.48 \mu \mathrm{mol}\right)$ and AIBN $(20 \mu \mathrm{L}$ of $7 \mathrm{mM}$ stock solution, $0.14 \mu \mathrm{mol})$ were dissolved in $(12.5 \mathrm{~mL}, 108.5 \mathrm{mmol})$ of styrene in a reaction flask equipped with a stir bar. This mixture was allowed to stir until the solids were completely dissolved. The mixture was then bubbled with $\mathrm{N}_{2}$ for 15 minutes, and placed in an oil bath at 65 ${ }^{\circ} \mathrm{C}$. After $24 \mathrm{~h}$, the flask was cooled to room temperature and the contents were diluted with dichloromethane and precipitated in hexanes (twice). The resulting polymer was suspended in boiling acetonitrile to remove residual poly(SM) homopolymer. The polymer was then dried overnight under vacuum to yield a powdery solid $(0.806 \mathrm{~g})$. SEC (polystyrene calibration): $M_{\mathrm{n}}=$ $218 \mathrm{~kg} / \mathrm{mol}, \oplus=1.56 ;{ }^{1} \mathrm{H}$ NMR: $n(\mathrm{PS})=11,234$.

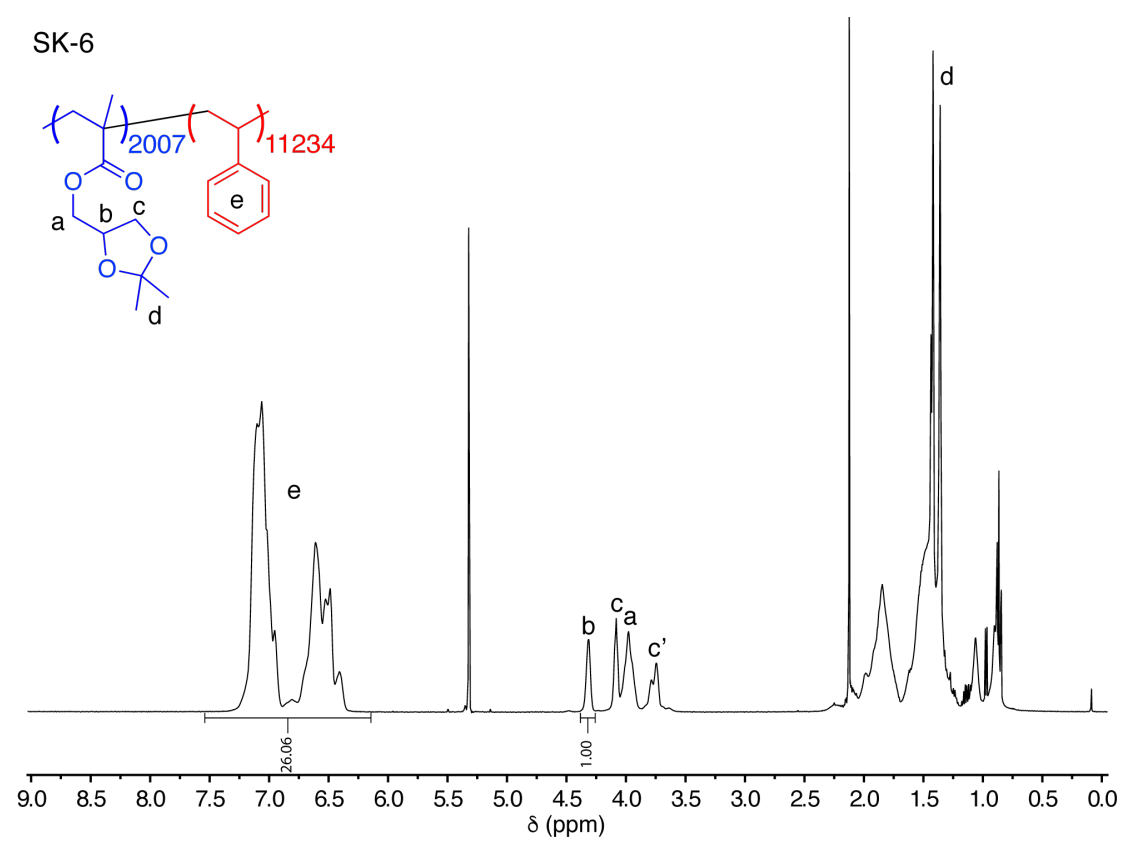



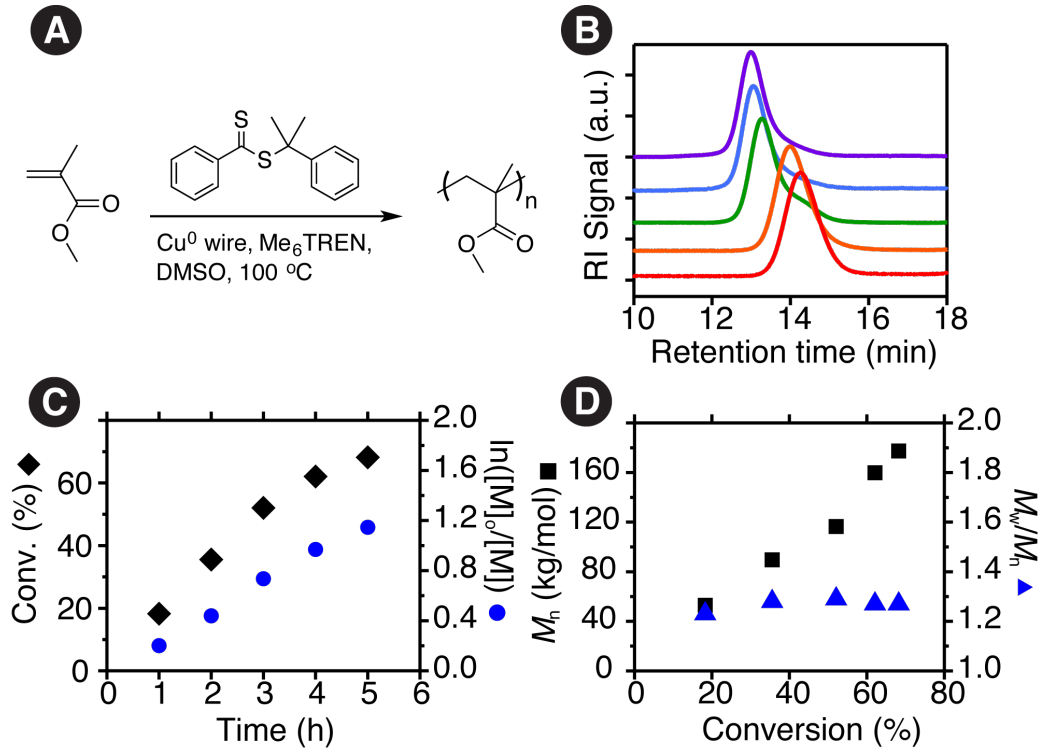

Figure S1. Polymerization of MMA ([MMA]:[CDB]:[Me ${ }_{6}$ TREN] $=2,000: 1: 1$ ). (A) Synthetic scheme, (B) SEC analysis of PMMA homopolymers, (C) first-order kinetic plot, and (D) evolution of molecular weight and dispersity with conversion.
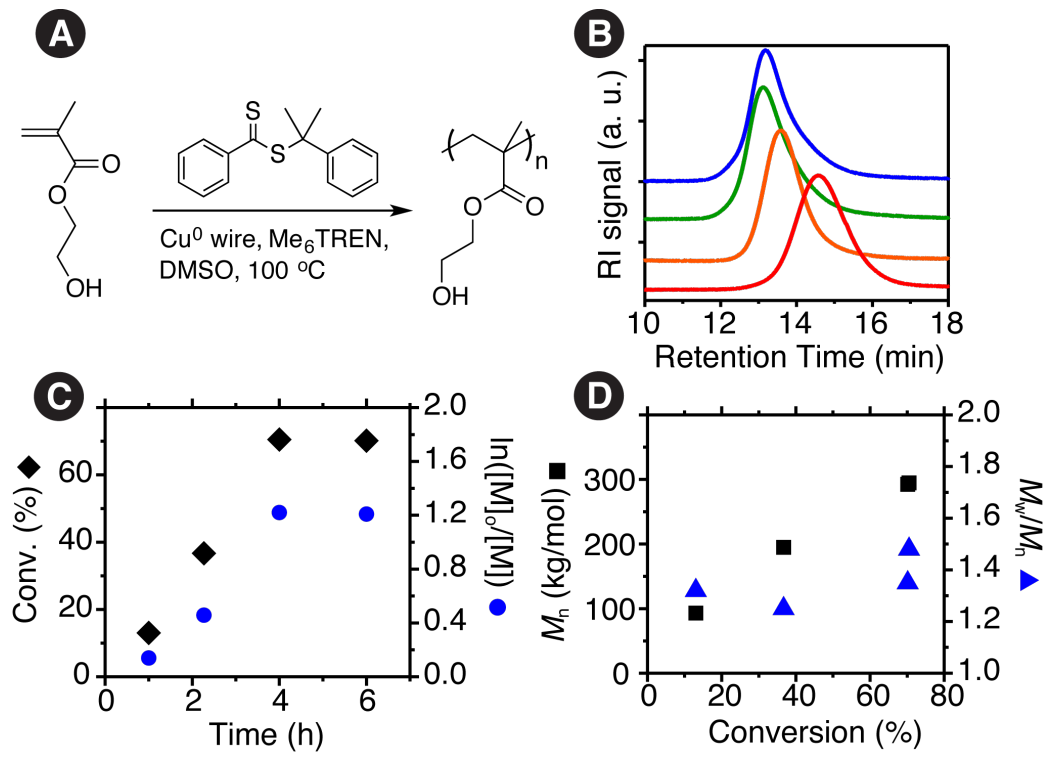

Figure S2. Polymerization of HEMA ([HEMA]:[CDB]:[Me ${ }_{6}$ TREN] $=2,000: 1: 1$ ). (A) Synthetic scheme, (B) SEC analysis of Acetylated PHEMA homopolymers, (C) first-order kinetic plot, and (D) evolution of molecular weight and dispersity with conversion. 


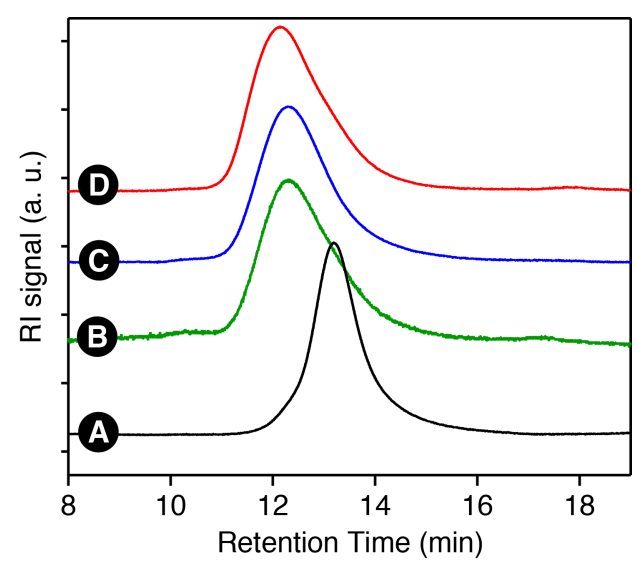

Figure S3. SEC traces of (a) PSM precursor, and PSM-PS block copolymer SK-3: (b) as synthesized, (c) after washing in boiling acetonitrile, and (d) after washing in cyclohexane.

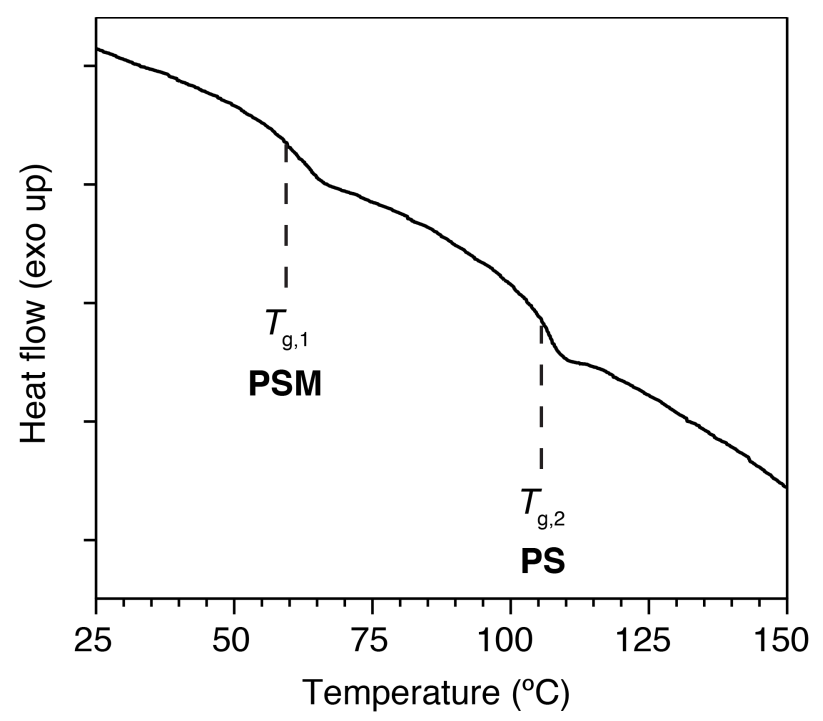

Figure S4. Differential scanning calorimetry analysis of PSM-PS block copolymer. 

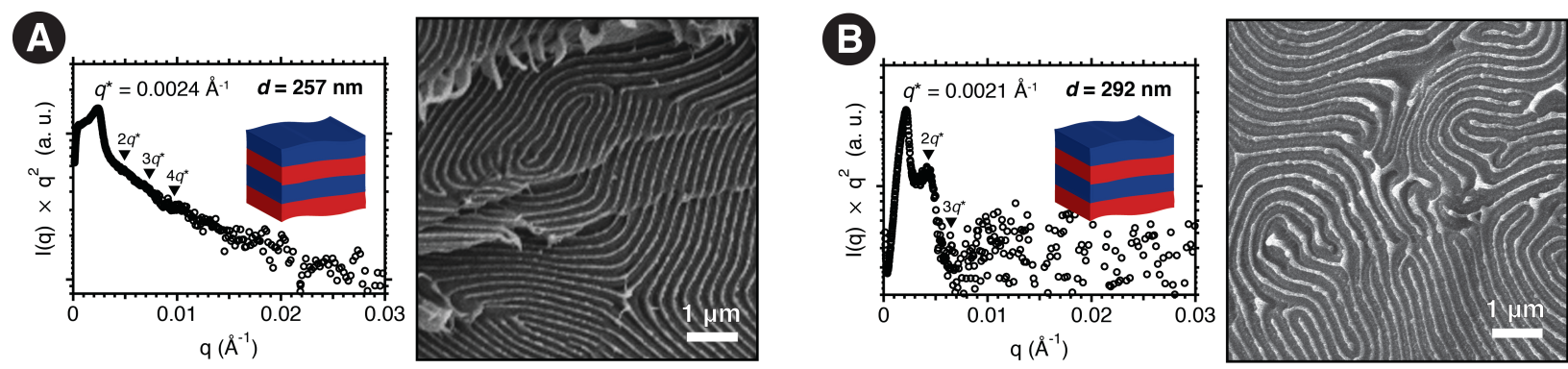

Figure S5. USAXS and SEM analysis of PSM-PS block copolymers (A) SK-5, and (B) SK-6. 